\title{
Patient perspective: Roger Boyes
}

\author{
Roger Boyes
}

London

Covid-19 survivors who, like me, were in the intensive care unit (ICU), are still a pretty exclusive club. Just $20 \%$ of those who have received mechanical ventilation in the UK have been discharged alive, says the largest detailed description of covid-19 in Europe (a preprint); 53\% have died, and 27\% remained in hospital at the time of reporting. ${ }^{1}$

For now, I'm on the "good luck" team-yet I can't escape a sense of abandonment. From a dozen or more highly trained ICU professionals around my bed less than two months ago, my point of contact with the health system has been reduced to an occasional phone consultation with my GP, who I've met only once in the flesh. This steep slide shouldn't be a problem-I'm alive, right? - but somehow it is. The number of survivors like me will grow and, like me, they're likely to be left in a rehab limbo.

I was admitted to St Thomas' Hospital, London, in March with pneumonia related covid-19, intubated in the course of a respiratory peri-arrest, shuttled between ventilator and sedation, covered with Tazocin, and given a 10 day course of remdesivir. When I was moved to the rehab ward-four patients in different states of disrepair-I grew stronger and became less of a patient, more of an observer.

One thing very quickly became clear: a busy urban hospital faced with such a comprehensive emergency is not a place of rest and recovery. Patients called out for the solitary night nurse until shortly before dawn. Lights went on and off; monitors beeped incessantly. All of the patients, including me, were experiencing covid-19 delirium: vivid, often horrifying hallucinations. Perhaps we were also grappling with the trauma of what had happened in the ICU. How would we know? I can't recall a single face-to-face conversation with a neurologist. One of the patients died.

\section{Testing and discharge}

When I left, five weeks later, I was wobbly but relieved. The hospital, led by the physio, had prepared the ground: consulting the local council, ensuring that my home was safe, and checking to make sure that my son would be keeping an eye on me. Overlapping rehab teams came into play-some with links to the hospital, others with Southwark Council, and another from the British Red Cross who offered to shop for me. There were not only physios and nutritionists and occupational therapists but also, at last, a neuropsychiatrist at the end of the line. In that first week my apartment became so crowded that a nurse had to wait outside the door while another team conducted their tests.

Ultimately, however, it was just that: testing to satisfy that they'd completed their duty of care. One therapist watched me make coffee to ensure that I could still assess the danger of an open flame. Another pushed against my legs to see whether my muscles were up to it. Blood pressure meds were adjusted to halt any dizziness.

And then they disappeared, their task apparently complete. The neuropsychiatrist rang once to check that I could still recite the months of the year backwards and pronounced me OK; so did the others, in an eager stampede to discharge me. Yet none of these (entirely welcome) visits really dealt with my needs. How was I to repair my broken sleeping pattern? In hospital I was hyper-alert, sensing danger everywhere. At home, although the hallucinations had receded, my nerves still jangled. And I had memory loss - of certain words when under pressure but also of whole episodes. Did this derive from the ICU trauma, the drugs, the fever, the prolonged sleep deprivation? Would it get better "over time," as one occupational therapist blithely assured me, or was something deeper going on? Who would help me get to the root of the missing days?

Not my GP-who did, however, treat my chronic post-hospital constipation. I shouldn't generalise from a hospital/care situation in a very special, protracted medical emergency. ICUs are designed to save lives, not rebuild them. Care teams are not nannies but rather temporary props. What they do, they do very competently. But I'm worried that covid-19 patients are falling through the cracks.

One of the patients in my ward, although telling the nurses that he couldn't wait to go home, told me that he was terrified at the prospect. He even ripped out his tubes, letting the blood flow freely, to try to prolong his stay. In the scramble to keep him alive, everyone had overlooked his brain and his psyche. 
Competing interests: I have read and understood BMJ policy on declaration of interests and have no relevant interests to declare.

Provenance and peer review: Commissioned; not externally peer reviewed.
1 Wise J. A third of covid-19 patients admitted to UK hospitals die. BMJ 2020;369:m1794. 10.1136/bmj.m1794 32354787

Published by the BMJ Publishing Group Limited. For permission to use (where not already granted under a licence) please go to http://group.bmj.com/group/rights-licensing/ permissions 